\section{Commentary: January 21, 2020: The beginning of the end or the end of the beginning?}

\author{
George L. Hicks, MD
}

January 21, 2020, was a day that changed the world as we know it, for it was on that date that the Centers for Disease Control and Prevention confirmed that Washington State had reported the first US case of coronavirus disease 2019 (COVID-19) from person-to-person transmission. Doing so raised the alarm of the potentially devastating consequences of a pandemic. The months to come revealed the horrors of a worldwide pandemic, fraught with anxiety about rates and number of infections, hospital and health care resources, as well as societal and economic upheaval. The question proposed in the title is yet to be answered and many other questions remain.

Ad and colleagues ${ }^{1}$ surveyed institutions in North America in an attempt to analyze the effect of COVID-19-19 infections on hospital resource utilization, cardiac surgery volume, and case mix. The authors divided the institutions into high burden of COVID-19 infections ( $>100$ beds occupied) and low burden $(<100$ beds) to understand the relative effect hospitalizations for COVID-19 infections had on cardiac surgery volume and case mix. The survey had a $40 \%$ response rate and included 67 institutions that perform adult cardiac surgery with diverse geographic distribution across North America, representing annualized case volumes of 60,452 in 2019. Nonurgent surgery was stopped during March 2020 in the majority of centers $(96 \%)$, resulting in a $45 \%$ decline from baseline with significant regional variation. Hospitals with a high burden of inpatients with COVID-19 demonstrated similar trends of decline in total volume as did centers in low burden areas proportionally. The observational study revealed a relative increase of coronary artery bypass grafting surgery (high burden group, $+7.2 \%$ vs low burden group, $+4.2 \% ; P=.550)$, extracorporeal membrane oxygenation

From the Division of Cardiothoracic Surgery, Department of Surgery, University of Rochester Medical Center, Rochester, NY.

Disclosures: The author reported no conflicts of interest.

The Journal policy requires editors and reviewers to disclose conflicts of interest and to decline handling or reviewing manuscripts for which they may have a conflict of interest. The editors and reviewers of this article have no conflicts of interest.

Received for publication July 15, 2020; revisions received July 15, 2020; accepted for publication July 15, 2020; available ahead of print July 19, 2020.

Address for reprints: George L. Hicks, MD, Division of Cardiothoracic Surgery, Department of Surgery, University of Rochester Medical Center, 401 Elmwood Ave, Rochester, NY 14642 (E-mail: George_Hicks@URMC.Rochester.edu).

J Thorac Cardiovasc Surg 2021;162:904-5

$0022-5223 / \$ 36.00$

Copyright (c) 2020 by The American Association for Thoracic Surgery

https://doi.org/10.1016/j.jtcvs.2020.07.054

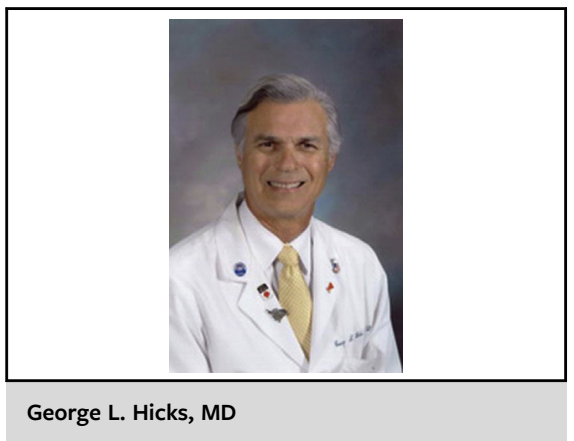

CENTRAL MESSAGE

COVID-19 infections have

created large burdens and ex-

penses for many institutions,

influencing cardiac surgery,

health care economics, and so-

ciety. Many questions are yet to

be answered for the future.

(high burden group, $+2.5 \%$ vs low burden group, $0.4 \%$; $P=.328$ ), and heart transplantation (high burden group, $+2.7 \%$ vs low burden group, $0.4 \% ; P=.090$ ), and decline in valvular cases (high burden group, $-7.6 \%$ vs low burden group, $-2.6 \% ; P=.195)$. Transcatheter aortic valve replacement cases were excluded from the analysis.

The authors' survey analysis concluded that institutions with the largest COVID-19 burden had the greatest decline in elective cardiac surgery cases. These regions were predominantly the Northeast and Southwest and were mostly larger institutions that had to deploy significant proportions of their resources to provide real and anticipated health care for patients with COVID-19 infection. As noted in the Limitations section, the study is a snapshot in time- actually only 1 month - and doesn't really provide the granularity necessary to understand the devastating effects of COVID-19 infections across North America. However, it is an initial attempt to come to grips with this pandemic that has and will continue to change our lives.

Although the survey deals with COVID-19 burden and influence, we need answers to questions yet to be addressed:

1. How did the uneven burden among institutions affect not only cardiac volume and case mix, but also overall (eg, hospital mortality rates, cash flow, and assumption of debt)?

2. How many patients could not be admitted to hospital because of real or potential resource limitations?

3. How did the reduction in revenue and need for expensive intensive care unit stays influence high burden institutions' 
bottom line and cause need for deficit funding, reduction of nonessential personnel through furloughing, and loss of future savings by retirement benefit reduction?

4. What toll did the pressure and anxiety of treating highly contagious patients have on frontline health care workers and how many had serious sequelae related to COVID19 infection?

5. How will the reduction in case volume and change in cardiac care experience influence the training of resident physicians, the future of our profession?

6. How will we adapt our health care policies to protect in the future the most at-risk populations, including the elderly, African Americans, Hispanics, and the immunocompromised?

7. During this time of health care catastrophe and economic collapse, insurance companies continue to collect dividends without expenditures for elective inpatient or outpatient procedures. Are any of the massed contingency funds for catastrophic events that remain going to the institutions with highest COVID-19 burden and crippling expense?

8. Will a vaccine be developed and used or the concept of herd immunity be proven so that the future of the world will appear brighter and able to return to more normal functioning?

Is it the end of the beginning or the beginning of the end? In a nation struggling to reopen, COVID-19 infections continue to rise in some areas at an alarming rate. Fortunately, deaths due to infections have not increased proportionally and we can hope that some lessons have been learned. Self-quarantining when symptoms are present, practicing social distancing and wearing face masks, avoiding large inside gatherings, and having overall respect for the health of others remain critical. Most importantly, the effects and devastation of the pandemic serve as a chilling reminder of how fragile our existence is and how interrelated global health can be. Let us hope it is the beginning of the end, but we remain on that tenuous pandemic seesaw such that we can only do our part to maximize the chances that the months to come will bring social, health, and economic wellness to all.

\section{Reference}

1. Ad N, Luc JGY, Nguyen TC, the COVID-19 North American Cardiac Surgery Survey Working Group. Cardiac surgery in North America and coronavirus disease 2019 (COVID-19): regional variability in burden and impact. J Thorac Cardiovasc Surg. 2021;162:893-903.e4.
See Article page 893

\section{Commentary: Cardiac surgery in North America: Facing a new normal}

\author{
Camilo A. Gomez, MD, ${ }^{\mathrm{a}}$ and Tomas A. Salerno, $\mathrm{MD}^{\mathrm{b}}$
}

From the ${ }^{\mathrm{a}}$ Division of Cardiovascular Diseases, Department of Medicine, University of Miami Miller School of Medicine, Miami, Fla; and ${ }^{\mathrm{b}}$ Division of Cardiothoracic Surgery, University of Miami Miller School of Medicine, Jackson Memorial Hospital, Miami, Fla.

Disclosures: The authors reported no conflicts of interest.

The Journal policy requires editors and reviewers to disclose conflicts of interest and to decline handling or reviewing manuscripts for which they may have a conflict of interest. The editors and reviewers of this article have no conflicts of interest.

Received for publication June 29, 2020; revisions received June 29, 2020; accepted for publication June 29, 2020; available ahead of print July 13, 2020.

Address for reprints: Tomas A. Salerno, MD, Division of Cardiothoracic Surgery, University of Miami Miller School of Medicine and Jackson Memorial Hospital, PO Box 016960, JMH East Tower, Room 3072, Miami, FL 33101 (E-mail: TSalerno@med.miami.edu).

J Thorac Cardiovasc Surg 2021;162:905-6

$0022-5223 / \$ 36.00$

Copyright (C) 2020 by The American Association for Thoracic Surgery

https://doi.org/10.1016/j.jtcvs.2020.06.110

\section{Check for updates}

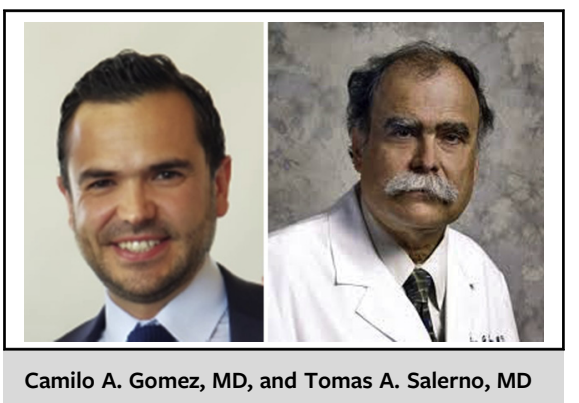

CENTRAL MESSAGE

COVID-19 has caused a paradigm

shift in referrals, volumes, and

cardiac procedures that favors

interventional procedures for

CAD and TAVR for aortic valve

diseases.

The coronavirus 2019 (COVID-19) pandemic profoundly affected the US health care system, leading to drastic 